\title{
Improving Postharvest Storage Quality of Cucumber Fruit by Modified Atmosphere Packaging and Biomaterials
}

\author{
İbrahim Kahramanoğlu and Serhat Usanmaz \\ Department of Horticultural Production and Marketing, Faculty of \\ Agricultural Sciences and Technologies, European University of Lefke, \\ Northern Cyprus, via Mersin 10 Turkey, 99780
}

Additional index words. chilling injury, decay incidence, fruit firmness, lemongrass oil application, propolis extract, sensory quality, weight loss

\begin{abstract}
The present study was conducted with the aim of increasing storage duration of cucumber fruits by using eco-friendly edible biomaterials and nanotechnology. Hence, the effects of postharvest-applied lemongrass oil (LO) and propolis extract (PEx), alone or in combination with modified atmosphere packaging (MAP), on the weight loss, fruit firmness, sensory index, chilling injury (CI), decay incidence (DI), and soluble solid concentration (SSC) of cucumber fruits were tested. Two different doses $(0.2 \%$ and $0.5 \%$ ) of both LO and PEx were tested in present study. Application of LO and PEx was performed by dipping the fruits into the solutions at $21 \pm 1{ }^{\circ} \mathrm{C}$ for 3 minutes; after drying for 30 minutes, fruits were transferred to a cold room and kept at $4.5 \pm 0.5{ }^{\circ} \mathrm{C}$ and $95 \%$ relative humidity (RH). Studies were continued for 24 days, and quality parameters were measured at 4-day intervals. Two-day shelf-life simulation was also applied to fruits after each interval, and the same quality parameters were observed. Results suggest that the combination of MAP bags with LO or PEx treatment provides better conditions for postharvest storage of cucumbers and that storage duration might be extended to 20 days. Fruits treated with LO or PEx and stored in MAP bags maintained weight and SSC, were firmer, showed lower DI, and expressed lower CI $(P<0.05)$ throughout storage.
\end{abstract}

Agrochemicals play a vital role in controlling pests and disease and have an important role in the preservation of the postharvest quality of fresh produce. Misuse or excessive use of agrochemicals may cause significant hazards on human health (Coulibaly et al. 2011). Fungicides are of great importance for preserving fresh produce during storage. However, agrochemical residues in fresh produce have been the subject of contentious public discussions through the world among consumers, the media, and scientists (Koch et al., 2017). The acceptability of agrochemicals is decreasing worldwide because of possible negative impacts on human health (Sharma et al., 2009). Therefore, developing alternatives to agrochemicals is an important subject for research. Current postharvest studies are mainly focusing on the use of biomaterials, including essential oils (EOs), edible coatings, and plant extracts to preserve storage quality in fresh produce (Silvestre et al., 2011). Previous studies have described a number of successful biomaterials in postharvest storage studies, including chitosan (Adiletta et al., 2018; Gutiérrez-Martínez et al., 2018; Sharif et al., 2015), EOs (Kahramanoğlu 2019;

Received for publication 6 Aug. 2019. Accepted for publication 30 Aug. 2019

I.K. is the corresponding author. E-mail: ikahramanoglu@ eul.edu.tr.
Pavela and Benelli 2016; Prakash et al., 2015), PEx (Kahramanoğlu et al., 2018; Özdemir et al., 2010), plant extracts (Gatto et al., 2016; Obagwu and Korsten 2003), edible coatings (Dang et al., 2008; Panahirad et al., 2019; Saucedo-Pompa et al., 2009), and organic salts (Troyo and Acedo, 2019). In addition, MAP is an important nanotechnology for maintaining postharvest quality and upgrade the storage duration of fresh produce (Caleb et al., 2013). It has been reported to reduce respiration, which prevents weight loss and protects quality, and also to prevent CI and reduce microbial growth (Day, 2001; Gil et al., 1997).

Cucumber (Cucumis sativus L.) is an economically important crop; it is used for pickling and eaten fresh. Cucumber fruits are a good source of antioxidants, magnesium, and vitamin $\mathrm{C}$ and are rich in dietary fiber (Shi et al., 2015). However, cucumber fruits have a short storage duration, limited to less than $14 \mathrm{~d}$ due to loss of weight and firmness, discoloration, and fungal infections (Bahnasawy and Khater, 2014; Martin-Belloso and Fortuny, 2011). EOs (i.e., cinnamon oil) and chitosan have previously been tested and reported to have inhibitory effects on fungal rot and prevent weight loss on cucumber fruits (Carmo et al., 2008; de Sousa et al., 2012). Cold storage at $5{ }^{\circ} \mathrm{C}$ (Wang and Zhu, 2017), short-term hot water application (Nasef, 2018), ozone treatment (Glowacz et al., 2015), and MAP
(Manjunatha and Anurag, 2014) were also tested and found to be effective in preventing cucumber senescence. To the best of the authors' knowledge, no previous studies have been conducted on the effects of LO and propolis on the postharvest quality of cucumber fruits. MAP was previously tested and found to be effective, but the combination of LO and propolis has not been tested on cucumber fruits. The objective of present study was to test the effects of postharvestapplied LO and propolis, alone or in combination with MAP, on the weight loss, fruit firmness, sensory index, CI, DI, and SSC on cucumber fruit stored at $5{ }^{\circ} \mathrm{C}$.

\section{Materials and Methods}

Cucumber fruits (Cucumis sativus L. 'Falconstar') in the current study were harvested at commercial maturity (firm, turgid, dark green, and succulent) from a greenhouse located in Yedidalga, Lefke province, in northern Cyprus. The fruits were transported to the laboratory within $1 \mathrm{~h}$ and selected for consistent maturity and appearance; fruits with any mechanical or biological damage were not included.

Lemongrass (Melissa officinalis L.) oil and propolis extract were tested as biomaterials for preservation of postharvest quality of cucumber fruits. One hundred percent pure LO (Olimpos Melissa) was procured from Altug Medical Ltd (Denizli, Turkey). The material was first dissolved in $70 \%$ ethanol $(10 / 90 \mathrm{v} / \mathrm{v})$. Pure water was then added to the solution as suggested by Kahramanoğlu et al. (2018) to prepare $0.2 \%$ and $0.5 \%$ doses of LO. Crude propolis was collected from Bağliköy province, northern Cyprus. Preparation of the $0.2 \%$ and $0.5 \%$ doses of PEx was performed by the same means as LO.

In addition to the biomaterials, a MAP bag was also tested. The bags were built from low-density polyethylene film with semipermeable characteristics and were procured from Dekatrend (Trendlife, Bursa, Turkey). The MAP bags were designed to work with $5 \pm 0.25 \mathrm{~kg}$ of cucumber fruits. The bags are sealed with atmospheric air after filling with cucumber fruits and capable of regulating inner air composition to $\approx 10 \%$ to $15 \% \mathrm{CO}_{2}$ and $5 \%$ to $10 \% \mathrm{O}_{2}$. The packaging material allows gas transfer and venting of excessive ethylene gas and RH. Before marketing the MAP bags, manufacturers perform studies to determine transfer capacity and crop metabolism to achieve favorable gas concentrations for successful preservation of the products. After sealing the bags, cucumber fruits continue respiration, and the $\mathrm{O}_{2}$ concentration in the headspace decreases while the $\mathrm{CO}_{2}$ concentration increases until reaching a previously determined equilibrium. Therefore, respiration of the product and the microbial activity slow down, improving the storage quality and duration of the crops.

The fruits were randomly divided into 10 groups (by number of treatments) of 192 fruits. Thus, these 192 fruits were divided into four equal groups (replications). The 

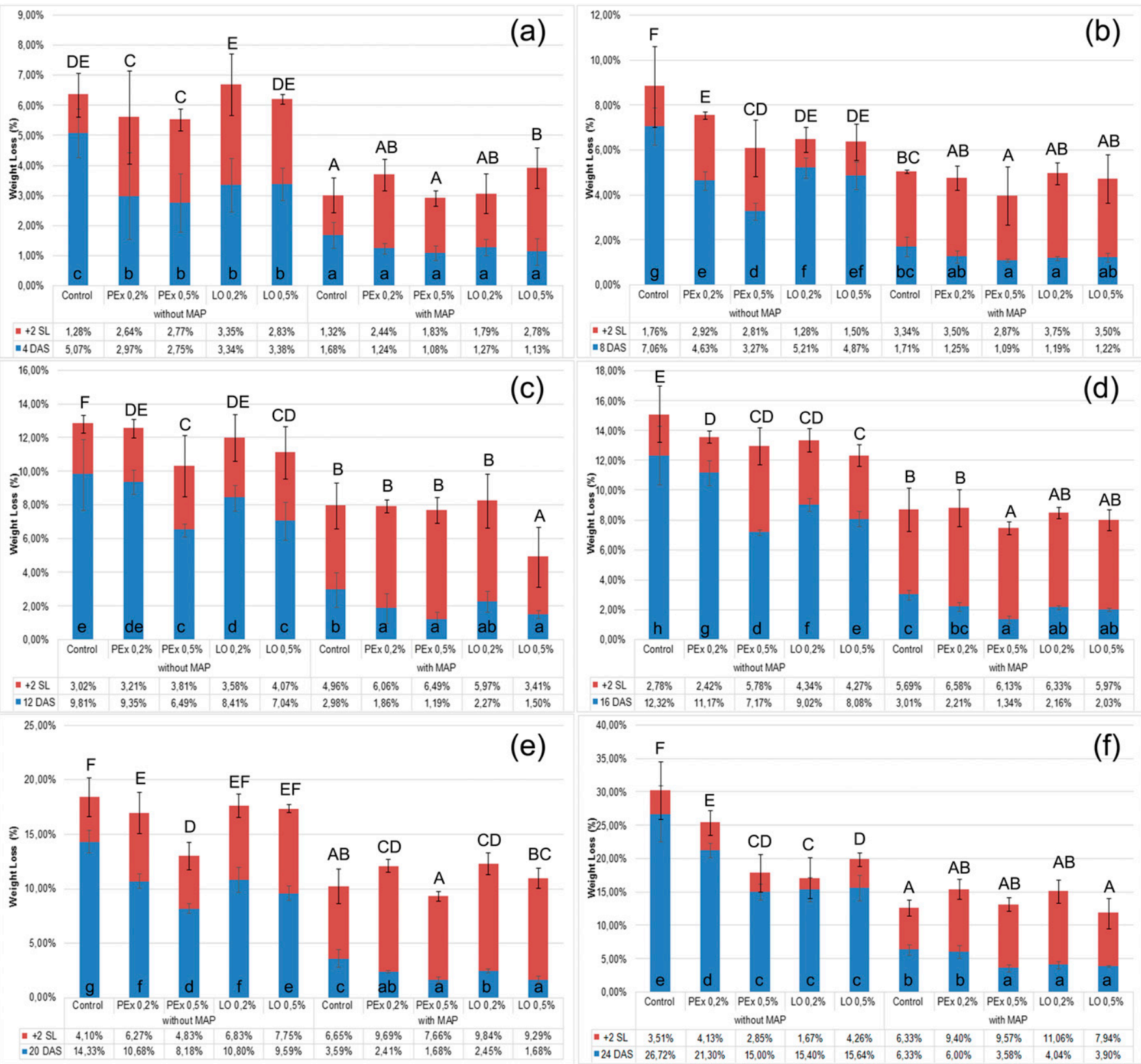

Fig. 1. Effects of different treatments on the weight loss of cucumber fruits during $24 \mathrm{~d}$ of storage. (A) Four days after storage (DAS), (B) 8 DAS, (C) 12 DAS, (D) 16 DAS, (E) 20 DAS, and (F) 24 DAS. LO = lemongrass oil; PEx = propolis extract; SL = shelf life. Values followed by the same letter or letters within the same storage time are not significantly different according to Duncan's multiple range test at $P \leq 0.05$. Small letters are used for the comparison of storage duration in cold rooms, and capital letters are used for the SL periods.

treatments of present study were as follows: 1) control, 2) LO $0.2 \%$, 3) LO $0.5 \%$, 4) PEx $0.2 \%, 5)$ PEx $0.5 \%, 6)$ Control + MAP, 7) LO $0.2 \%+$ MAP, 8) LO $0.5 \%+$ MAP, 9) PEx $0.2 \%+$ MAP and 10) PEx $0.5 \%+$ MAP. Application of the LO and PEx was performed by dipping the fruits into given solutions at $21 \pm 1{ }^{\circ} \mathrm{C}$ for $3 \mathrm{~min}$. After dipping, fruits were kept at ambient room temperature $\left(21 \pm 1{ }^{\circ} \mathrm{C}\right)$ to dry the surface moisture by fan and cooled for $30 \mathrm{~min}$; after this procedure, bagging into MAP was performed for the fruits in MAP treatment groups. After the completion of the all applications, fruits (eight from each of four replications) were transferred to a cold room and kept at $4.5 \pm 0.5^{\circ} \mathrm{C}$ and $95 \% \mathrm{RH}$. Studies were continued for $24 \mathrm{~d}$, and a total of 32 fruits were taken out from each treatment at 4-d intervals $(4,8,12,16,20$, and $24 \mathrm{~d})$ to measure the quality parameters. Half of these 32 fruits were measured at that time, and other half was kept at room temperatures $\left(24 \pm 1{ }^{\circ} \mathrm{C}\right.$ and $\left.65 \% \mathrm{RH}\right)$ to simulate SL and then measured. Fruit weight of each individual fruit was performed and noted before the experiments. In addition, 16 fruits were selected at the beginning of the experiments, and fruit firmness and SSC were measured and noted. At each 4-d interval, fruit weight, fruit firmness, SSC, CI, decay, and sensory quality were measured according to the following methods.
A digital scale $( \pm 0.01 \mathrm{~g})$ was used to determine the weights of each individual fruit. The initial and final weights were used to calculate weight loss. First, final weight was subtracted from initial weight to determine the weight lost; this was then divided by initial weight. The result was multiplied by 100 to determine weight loss (\%). Fruit firmness $\left(\mathrm{kg} \cdot \mathrm{cm}^{-2}\right)$ was qualified by using hand penetrometer. Measurements were performed from four distinct locations around the median of each fruit. SSC of each fruit was measured with a hand refractometer as $\%$ Brix. Fruits were cut from the midpoint and squeezed by hand to obtain juice for the measurement of SSC. CI index of the cucumber fruits was measured by using the 0 to 4 

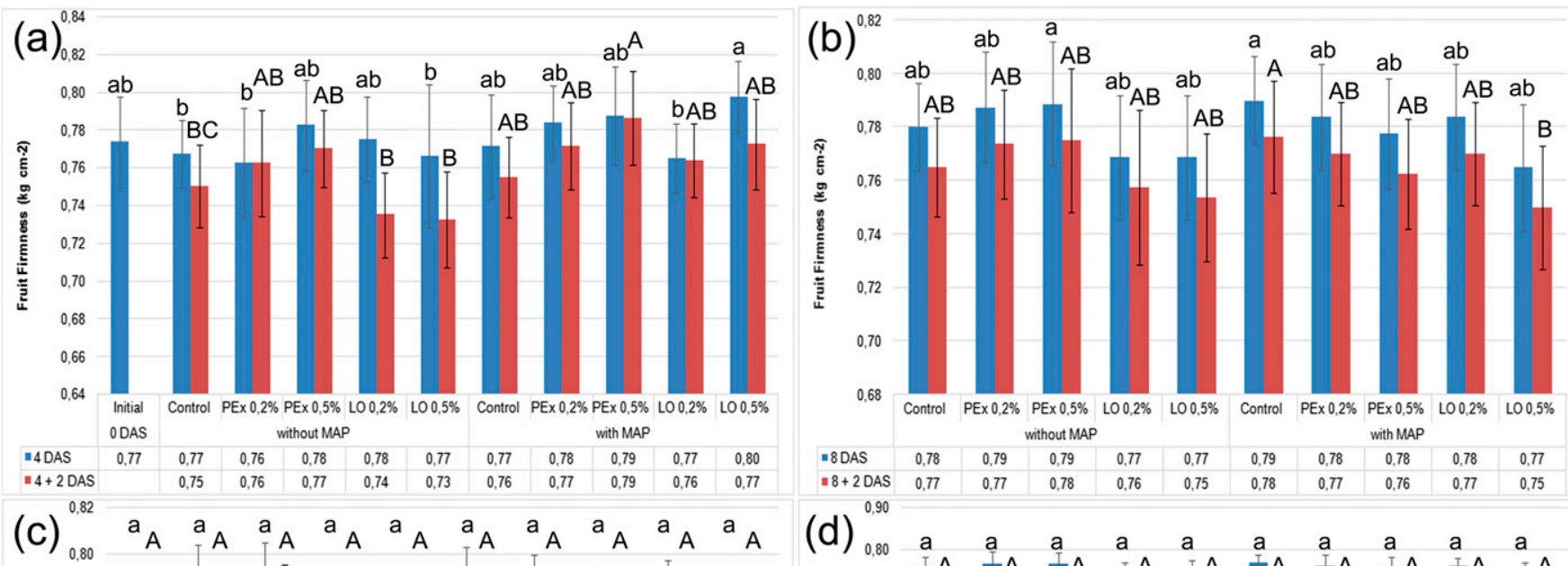

(d) 0.00
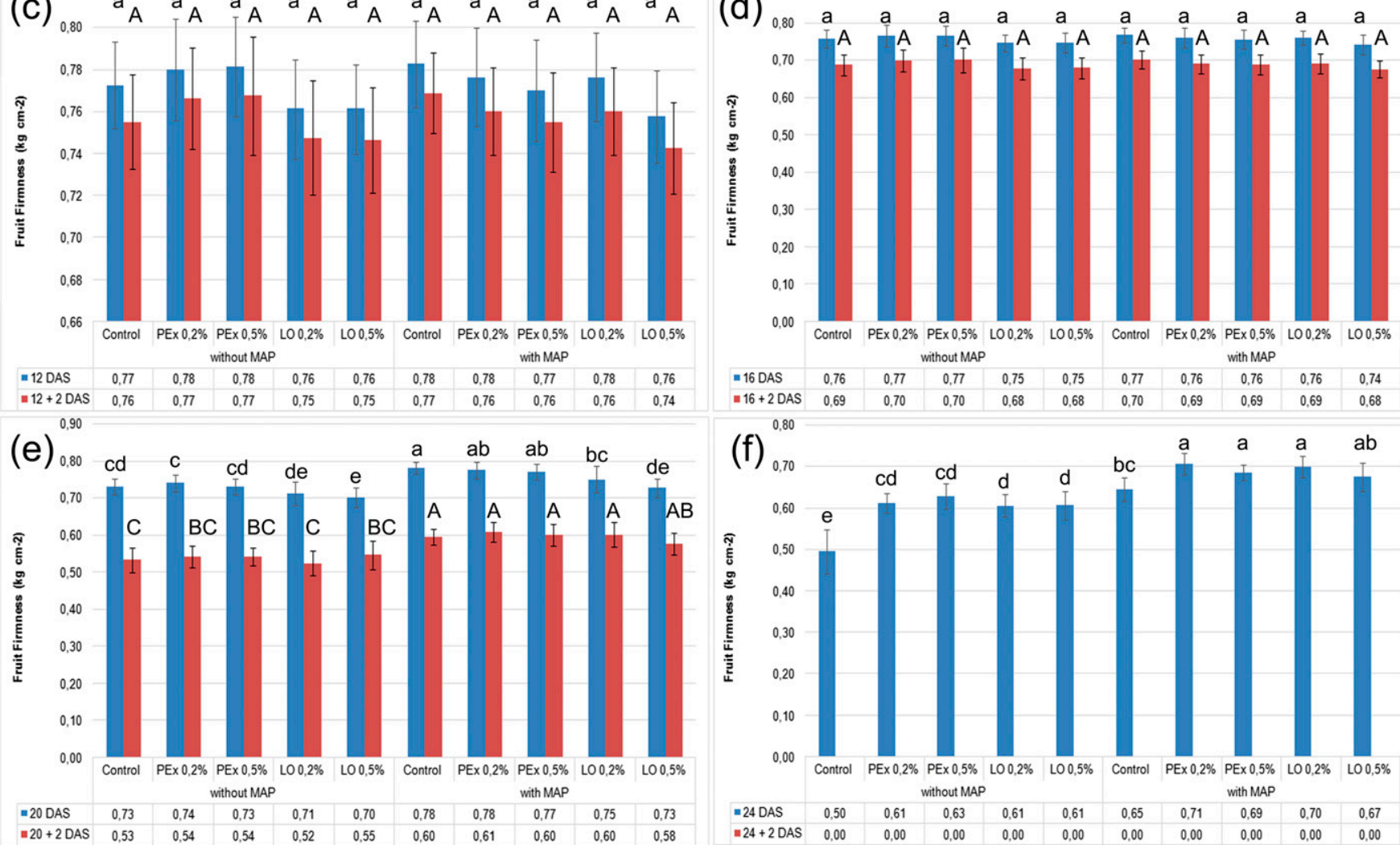

Fig. 2. Effects of different treatments on the firmness of cucumber fruits during $24 \mathrm{~d}$ of storage. (A) 4 DAS, (B) 8 DAS, (C) 12 DAS, (D) 16 DAS, (E) 20 DAS, and (F) 24 DAS. LO = lemongrass oil; PEx = propolis extract; $\mathrm{SL}=$ shelf life. Values followed by the same letter or letters within the same storage time are not significantly different according to Duncan's multiple range test at $P \leq 0.05$. Small letters are used for the comparison of storage duration in cold rooms, and capital letters are used for the SL periods.

scale reported by Dong et al. (2012), where 0 represents no signs of either surface pitting or dark watery patches, and $1,2,3$, and 4 represent $<25 \%, 25 \%$ to $50 \%, 51 \%$ to $75 \%$, and $>75 \%$, respectively. The scale numbers were used in the following formula to calculate CI index:

$$
\text { CI Index }=\frac{\begin{array}{c}
\sum[(\text { CI Scale }) \times(\text { number } \\
\text { of fruit at that } C I)]
\end{array}}{\begin{array}{c}
4 \times \text { total number of fruit in } \\
\text { each treatment }
\end{array}}
$$

The CI index ranged from 0 to 1 . The fruits with a CI index of 0.4 or higher were considered unacceptable for consumers. Sensory quality of cucumber fruits was evaluated according to the recession stage by using the 0 to 5 scale suggested by Han et al. (2015). Fruits' firmness, color, freshness, smell, and decay were evaluated to score the fruits; $0=$ excellent quality, $1=$ little damage, $2=$ slight damage, $3=$ moderate damage (limiting marketability), $4=$ heavy damage (limiting edibility), and $5=$ serious damage (inedible). The scores were used in the following formula to calculate sensory index: $\mathrm{SI}=[\Sigma(\mathrm{S} \times$ $\mathrm{Q})] / \mathrm{N}$, where $\mathrm{S}$ indicates the quantity of each degree, $\mathrm{Q}$ is the degree of decay, and $\mathrm{N}$ represents the total number of cucumbers in each treatment.

DI was observed according to the 0 to 3 scale formula of Cao et al. (2011). The visual evaluation of the each fruit was performed by using following scores: $0=$ no decay, $1=$ slight decay $(\leq 25 \%), 2=$ moderate decay $(25 \%<50 \%)$, and $3=$ severe decay $(>50 \%)$. After scoring the fruits, the following formula was used to quantify DI: DI $=\left\{\left[\left(1 \times \mathrm{N}_{1}\right)+\right.\right.$ $\left.\left.\left(2 \times \mathrm{N}_{2}\right)+\left(3 \times \mathrm{N}_{3}\right)\right] \times 100 /(3 \times \mathrm{N})\right\}$. In this formula, $\mathrm{N}$ represents the total number of fruit measured, and $\mathrm{N}_{1}, \mathrm{~N}_{2}$, and $\mathrm{N}_{3}$ were used to indicate the numbers of fruit showing the severity of decay.

Raw experimental data were summarized in Microsoft Excel, and the comparison of the effects of different treatments was determined by subjecting the data to analysis of variance and the mean separation was assessed with Duncan's multiple range test at $P \leq 0.05$. 

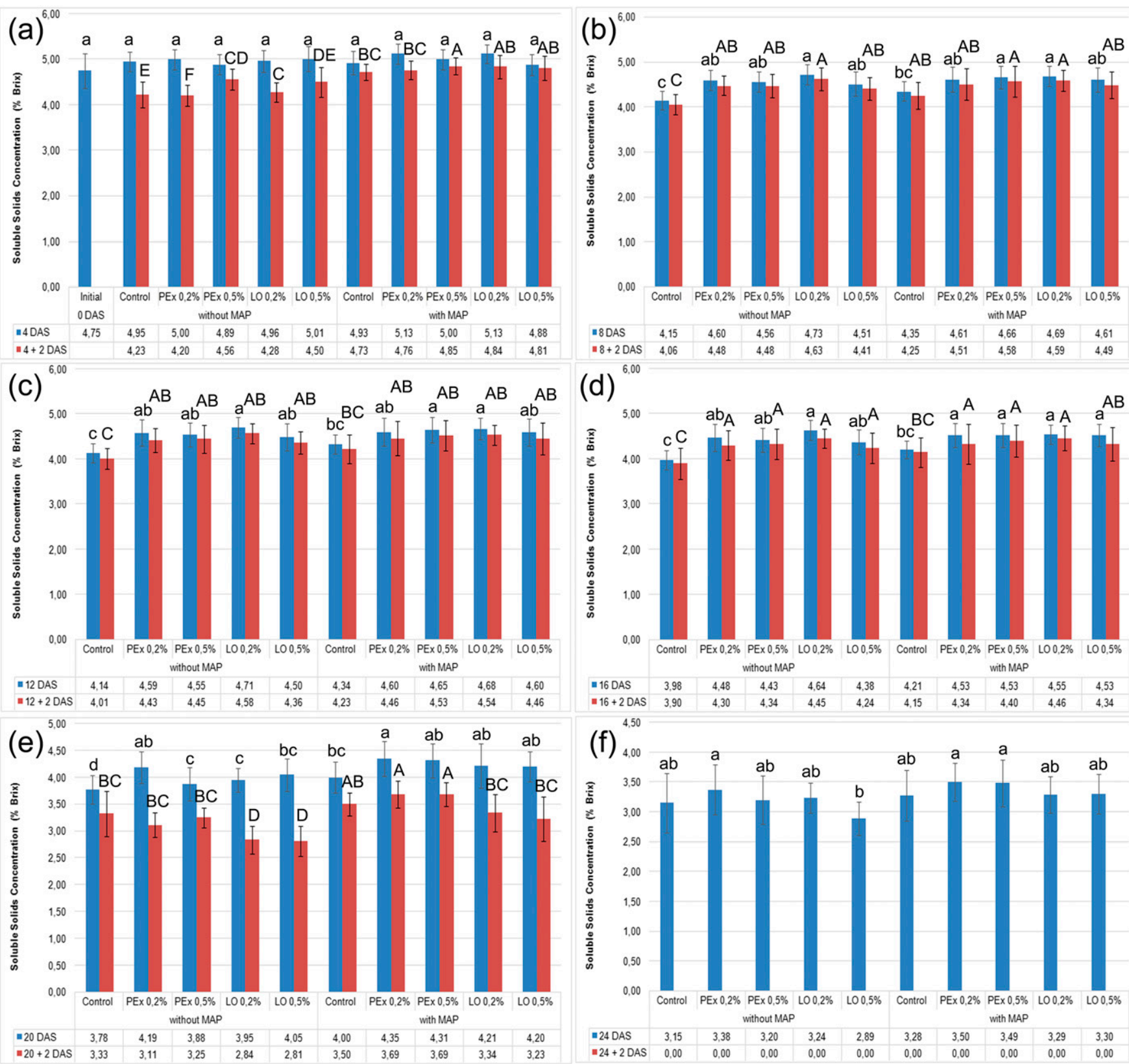

Fig. 3. Effects of different treatments on the soluble solids concentration of cucumber fruits during $24 \mathrm{~d}$ of storage. (A) Four days after storage (DAS), (B) 8 DAS, (C) 12 DAS, (D) 16 DAS, (E) 20 DAS, and (F) 24 DAS. LO = lemongrass oil; PEx = propolis extract; SL = shelf life. Values followed by the same letter or letters within the same storage time are not significantly different according to Duncan's multiple range test at $P \leq 0.05$. Small letters are used for the comparison of storage duration in cold rooms, and capital letters are used for the SL periods.

\section{Results}

Weight loss is an important indicator of the postharvest quality of fresh produce. Results of present study showed that untreated cucumber fruits exhibit an increasing trend in weight loss during storage, reaching $>25 \%$ in 24 d (Fig. 1). Moreover, it was also observed that, transferring fruits into ambient conditions for SL simulation ( $2 \mathrm{~d}$ ) is also causing important weight loss. Among the tested biomaterials both PEx and LO were found to be effective in preventing the weight loss. There were slight differences among the various doses of the test materials, but these differences were not statistically significant. When comparing the biomaterials, PEx was found to have higher influence on the prevention of weight loss than the LO. One of the most important results of present study is that MAP was found to have the highest impact on the prevention of weight loss. However, it was also observed that the combination of MAP with the PEx or LO improved efficacy and reduced weight loss. In $4 \mathrm{~d}$ of storage, control fruits reached to $5.07 \%$ weight loss. Weight loss of fruits treated with different doses of PEx and LO varied from $2.75 \%$ to $3.38 \%$. In contrast, fruits stored in MAP bags demonstrated only $1.68 \%$ weight loss in $4 \mathrm{~d}$ of storage. Weight loss decreased to between $1.08 \%$ to $1.27 \%$ when MAP was combined with PEx or LO. In addition to these important results, another crucial finding is that fruits stored in MAP showed higher weight loss under SL conditions than fruits stored without MAP. Weight loss in cucumber fruits showed a similar trend during storage, and similar results obtained $24 \mathrm{~d}$ after storage (DAS). At the end of the experiments, the lowest weight loss $(3.58 \%)$ was noted in MAP $+0.5 \%$ PEx application, was followed by MAP $+0.5 \%$ LO and MAP + $0.2 \%$ LO applications. No statistical difference was calculated among these three treatments. The weight loss of the three treatments after $24 \mathrm{~d}$ of storage was still less than the weight loss measured in control fruits at $4 \mathrm{~d}$ of storage. 

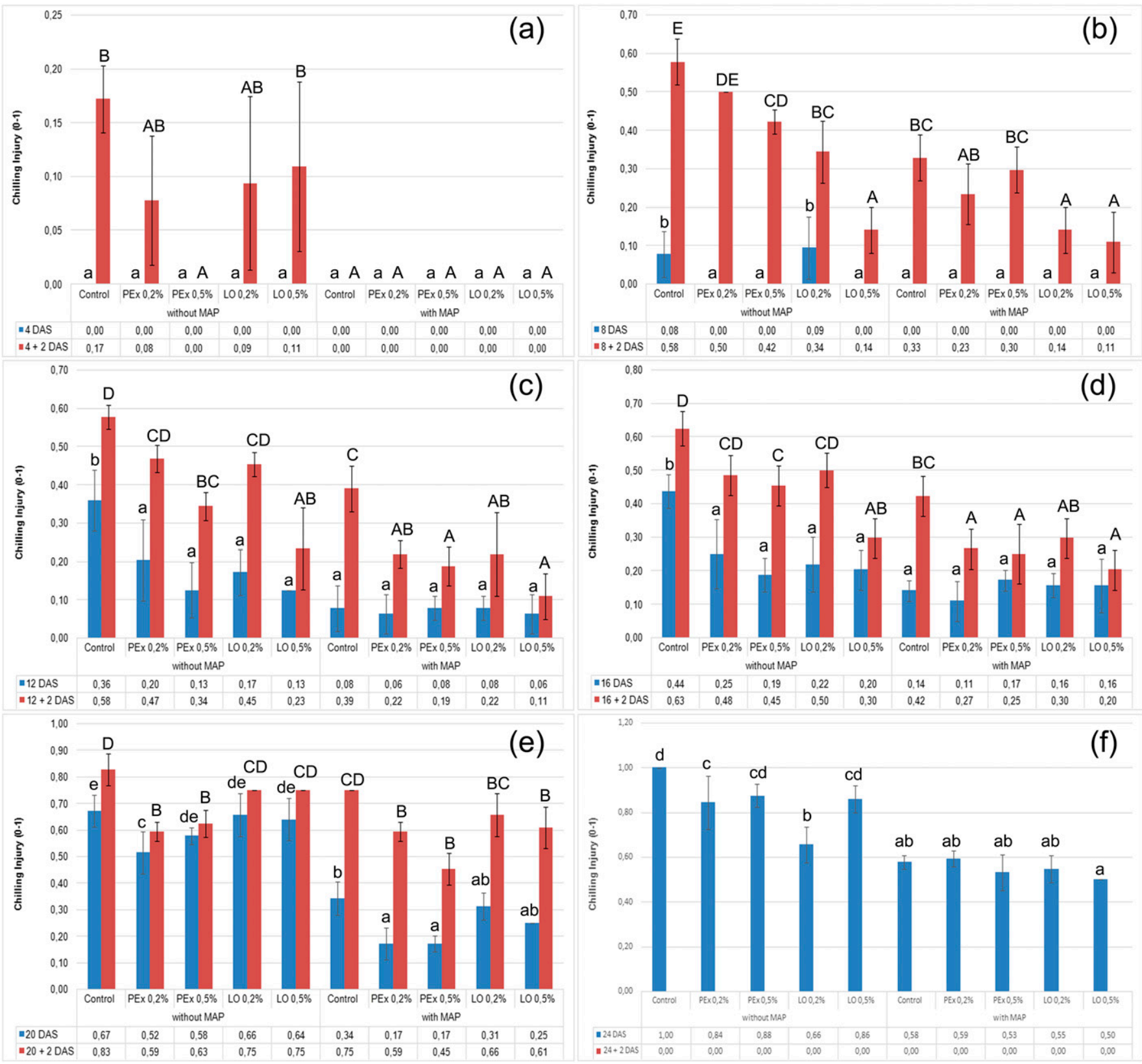

Fig. 4. Effects of different treatments on the CI of cucumber fruits during $24 \mathrm{~d}$ of storage. (A) Four days after storage (DAS), (B) 8 DAS, (C) 12 DAS, (D) 16 DAS, (E) $20 \mathrm{DAS}$, and (F) $24 \mathrm{DAS}$. LO = lemongrass oil; PEx = propolis extract; $\mathrm{SL}=$ shelf life. Values followed by the same letter or letters within the same storage time are not significantly different according to Duncan's multiple range test at $P \leq 0.05$. Small letters are used for the comparison of storage duration in cold rooms, and capital letters are used for the SL periods.

Fruit firmness is another important parameter used to determine fruit quality, and it is well known that postharvest handling and treatments influence fruit firmness. At the beginning of the experiments, average fruit firmness was measured as $0.77 \mathrm{~kg} \cdot \mathrm{cm}^{-2}$. The results obtained indicated that fruit firmness showed a decreasing trend during storage (Fig. 2). Moreover, exposing fruits to SL conditions caused a significant reduction in fruit firmness. During the first $16 \mathrm{~d}$ of storage, no significant difference in fruit firmness of the various treatments was observed. Thereafter, fruits stored in MAP bags were found to have higher fruit firmness than those stored without MAP. After SL simulation at $24 \pm$ $1{ }^{\circ} \mathrm{C}$, the fruits stored in MAP bags were found to have greater fruit firmness than those stored without MAP. Results suggested that the fruit firmness of cucumbers can be maintained for $20 \mathrm{~d}$ if stored in MAP bags at $4.5 \pm 0.5{ }^{\circ} \mathrm{C}$ and $95 \% \mathrm{RH}$. All fruits exhibited extreme decay after 24 DAS +2 SL and fruit firmness measurement was unable to perform.

The SSC of cucumber fruits was measured as $4.75 \%$ at the beginning of the experiments. During the first $4 \mathrm{~d}$ of storage, SSC of fruits increased slightly and was noted to be between $4.88 \%$ and $5.13 \%$. However, no significant difference was calculated between these values and the initial value. Hereafter, SSC of cucumber fruits showed a declining trend during storage.
Shelf-life conditions were also noted to reduce the SSC of cucumber fruits (Fig. 3). After $8 \mathrm{~d}$ of storage, fruits treated with any of the applications were found to have higher SSC than the untreated control fruits. Among these applications, the highest SSC was noted in the combination of MAP with PEx or LO and no significant difference was measured among these treatments. In $12 \mathrm{~d}$ of storage, fruit SSC in untreated control fruits decreased to $4.14 \%$, and the SSC of fruits treated with MAP and PEx or LO was between $4.60 \%$ and $4.68 \%$. The decreasing trend in SSC continued until the end of the experiments, but the efficacy of the treatments for maintaining SSC decreased after $24 \mathrm{~d}$ of storage. The difference between the 

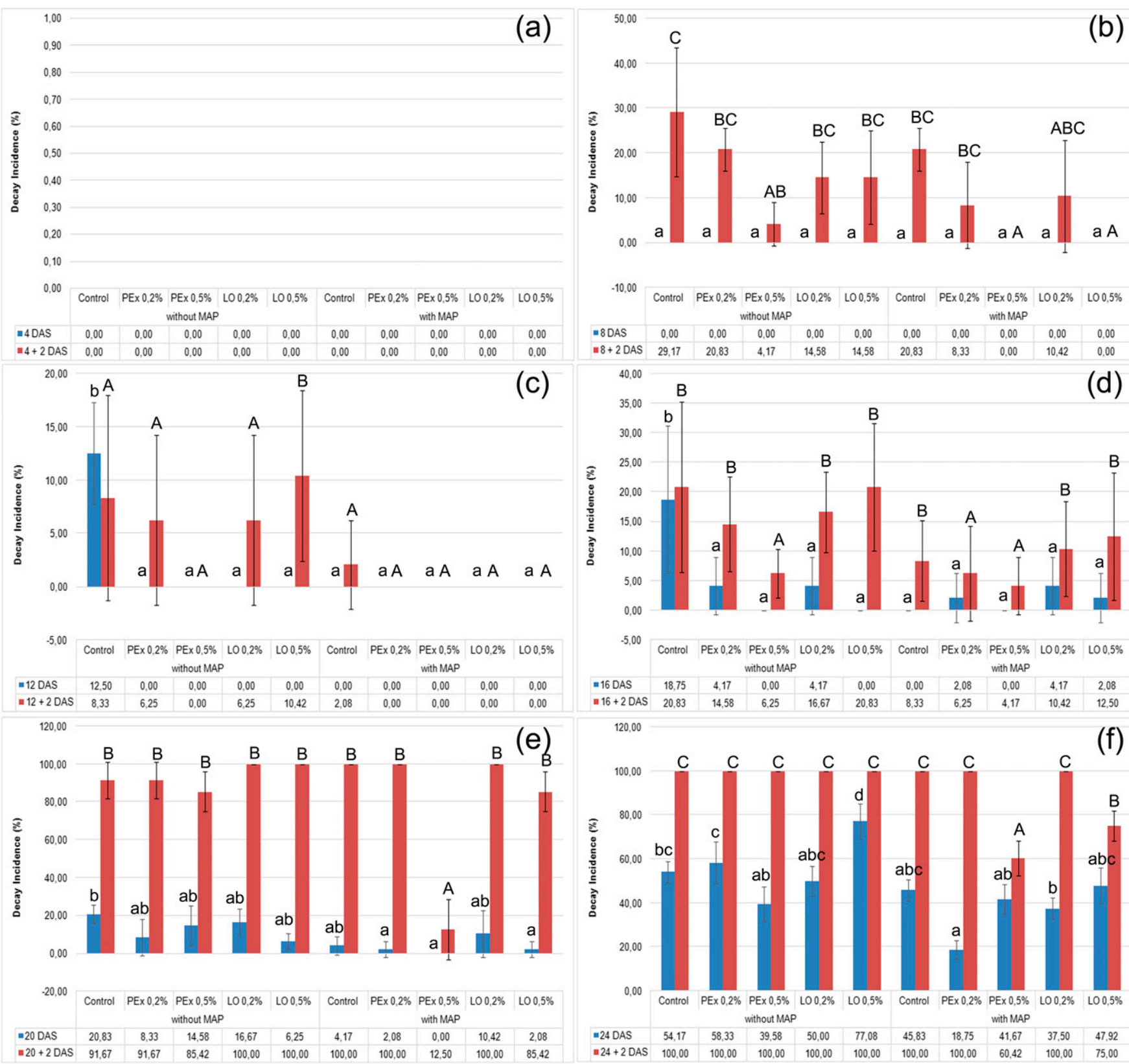

(b)
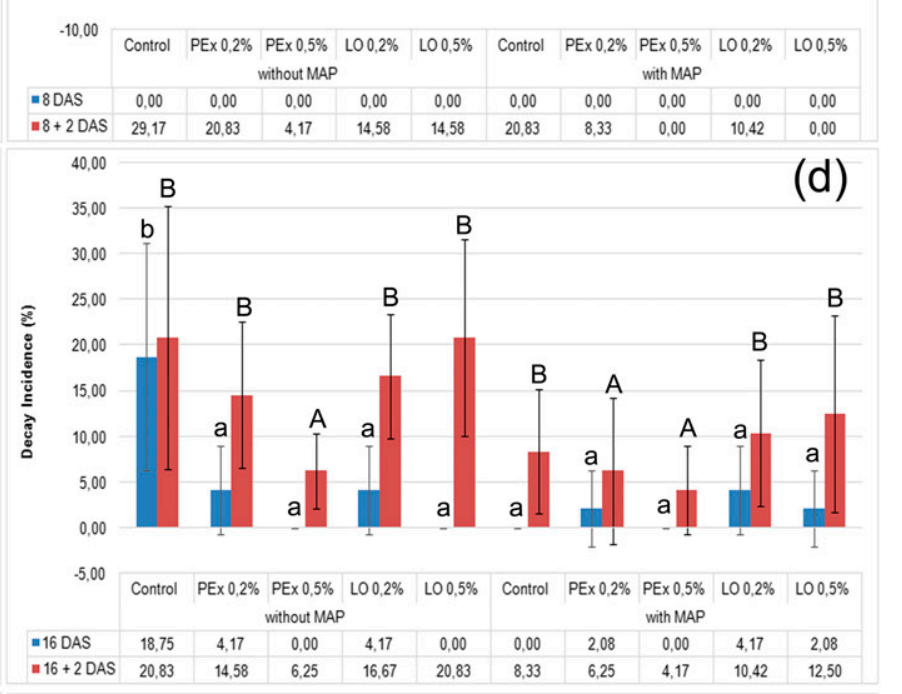

120,00

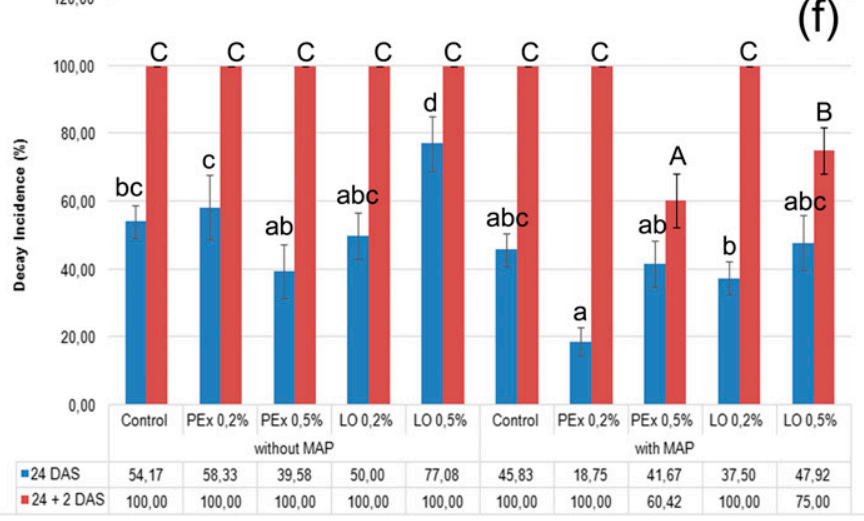

Fig. 5. Effects of different treatments on the decay incidence of cucumber fruits during $24 \mathrm{~d}$ of storage. (A) Four days after storage (DAS), (B) 8 DAS, (C) 12 DAS, (D) 16 DAS, (E) 20 DAS, and (F) 24 DAS. LO = Lemongrass oil; PEx = propolis extract; SL = shelf life. Values followed by the same letter or letters within the same storage time are not significantly different according to Duncan's multiple range test at $P \leq 0.05$. Small letters are used for the comparison of storage duration in cold rooms, and capital letters are used for the SL periods.

untreated and treated fruits decreased, and some of the treatments were found to be similar to untreated fruits in terms of fruit SSC. At the end of the experiments, the highest SSC was measured in fruits treated with MAP + PEx (both doses).

$\mathrm{CI}$ is a serious problem affecting many fruits and vegetables. Storing fruits at low but not freezing temperatures promotes to $\mathrm{CI}$ symptoms. It is a well-known phenomenon that CI symptoms mainly appear some days after storing at low temperatures. This was observed in the present study, and the first CI symptoms were observed at $4 \mathrm{DAS}+2 \mathrm{SL}$ (Fig. 4). However, CI symptoms were only observed in fruits stored without MAP. This result suggests that MAP improves fruits' resistance to CI. The acceptable CI limit for consumers is 0.4 . CI of untreated fruits and fruits treated with different doses of PEx exceeded the limit for consumers after 8 DAS +2 SL. CI of other fruits were below this level. CI showed an increasing trend during storage, but fruits stored in MAP bags were found to have significantly lower CI than the others. Untreated fruits were found to have acceptable CI at $12 \mathrm{~d}$ of storage, but the CI exceeded acceptable limits at $16 \mathrm{~d}$ of storage. All other treatments were found to prevent $\mathrm{CI}$ at $16 \mathrm{~d}$ of storage under $4.5 \pm$ $0.5{ }^{\circ} \mathrm{C}$. When fruits were taken out of cold storage to SL conditions, CI of all treatments increased rapidly. Fruits stored in MAP bags and treated with PEx or LO were still found to have acceptable CI. These results suggest that cucumber fruits can be stored until $20 \mathrm{~d}$ under $4.5 \pm 0.5^{\circ} \mathrm{C}$ and $95 \%$ RH if treated with PEx or LO and kept in MAP bags. However, CI increased rapidly and passed the acceptable level when fruits were transferred to SL conditions after $20 \mathrm{~d}$ of storage. The CI of all fruits was found to be greater than 0.4 after $24 \mathrm{~d}$ of storage.

Fruit decay is another problem in cucumber fruit storage. Results of the present study indicate that both treated and untreated fruits did not have decay problems at $4.5 \pm 0.5^{\circ} \mathrm{C}$ and $95 \% \mathrm{RH}$ storage conditions for $8 \mathrm{~d}$. Thereafter, fruits began to show signs of decay, but MAP bags were found to reduce DI (Fig. 5). Up to $12 \mathrm{~d}$ of storage, fruits 

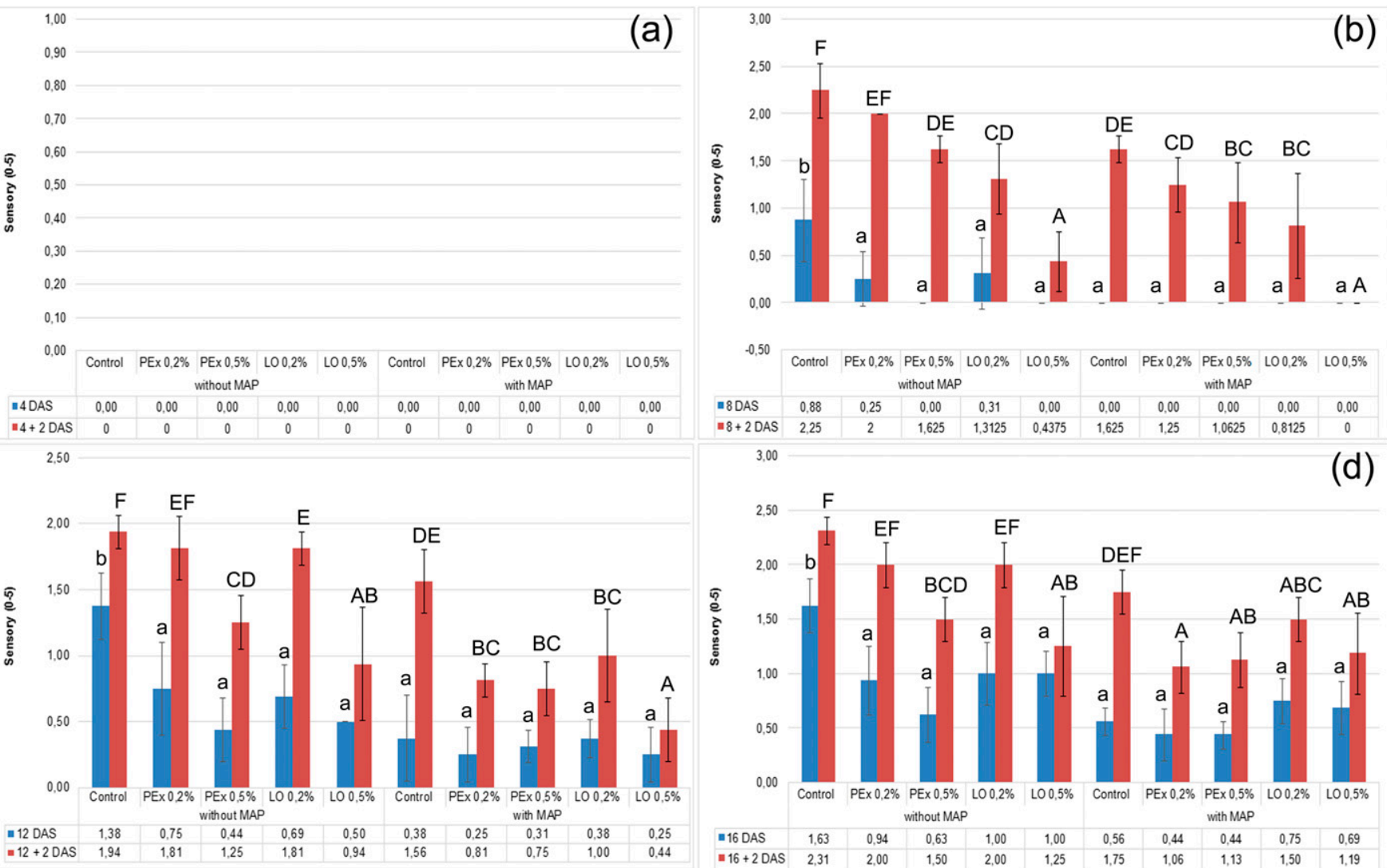

(d)
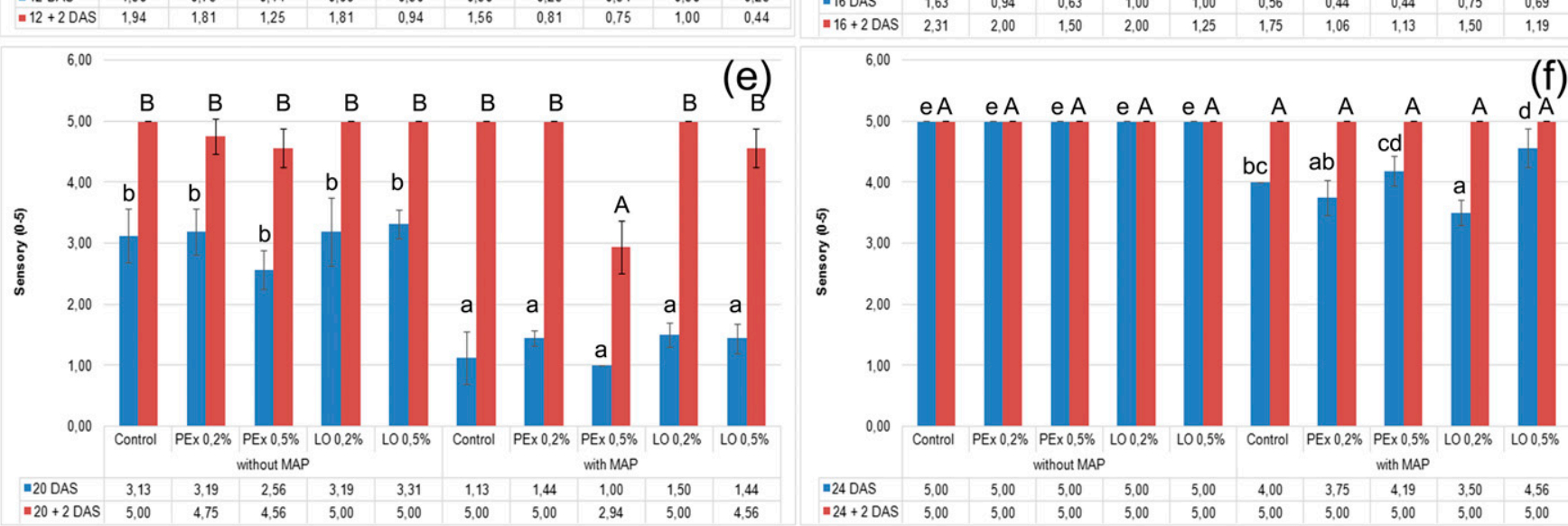

Fig. 6. Effects of different treatments on the sensory quality of cucumber fruits during 24 d of storage. (A) Four days after storage (DAS), (B) 8 DAS, (C) 12 DAS, (D) 16 DAS, (E) 20 DAS, and (F) 24 DAS. LO = lemongrass oil; PEx = propolis extract; SL = shelf life. Values followed by the same letter or letters within the same storage time are not significantly different according to Duncan's multiple range test at $P \leq 0.05$. Small letters are used for the comparison of storage duration in cold rooms, and capital letters are used for the SL periods.

treated with all treatments did not show decay. Storing fruits in MAP bags and treating with either of the biomaterials was also found to be an effective method to protect fruit from decay, not only in cold storage but also during SL, for $12+2 \mathrm{~d}$ of storage. Sixteen days of storage is the limit for those treatments, however, after which fruits began to show decay. After $20 \mathrm{~d}$ of storage, all fruits except those treated with $0.5 \% \mathrm{PEx}$ and stored in MAP bags had decay. DI reached $20.83 \%$ in untreated control fruits and was between $0.00 \%$ and $10.42 \%$ in the fruits treated with PEx or LO and stored in MAP bags. After the MAP $+0.5 \%$ PEx treatment, the highest influence, and therefore the lowest decay incidence, were mea- sured from MAP + $0.2 \%$ PEx and MAP + $0.5 \%$ LO. Thereafter, SL conditions promoted DI. Fruits treated with $0.5 \%$ PEx and stored in MAP bags showed $12.5 \%$ DI; the rest had greater than $85.42 \%$ DI after 20 $\mathrm{DAS}+2 \mathrm{SL}$.

Sensory quality is the last parameter studied but may be the most important for consumers. Results suggest that fruits do not have problems with sensory quality at 4 or $4+2 \mathrm{~d}$ of storage. A 0 to 5 scale was used to rate sensory quality (recall that $0=$ excellent quality and $5=$ inedible). The first decline in sensory quality was observed at $8 \mathrm{~d}$ of storage in the untreated control fruits and in fruits treated with the lower doses of PEx and LO (Fig. 6). The sensory quality of those fruits was between 0.00 and 0.88 , indicating normal smell, freshness, and firmness; a faint loss of green color of the peel; and visible decay. This was acceptable for consumers, but when fruits were transferred to SL conditions, all fruits, except those stored in MAP bags and treated with $0.5 \% \mathrm{LO}$, had higher scores, reaching 2.25 (more than a slight increase on the sensory index). After $12 \mathrm{~d}$ of storage, sensory quality of all fruits began to decrease. However, fruits stored in MAP bags were of better quality than the others, as demonstrated by a lower score on the sensory index. Even at $16 \mathrm{~d}$ of storage, sensory quality scores of fruit stored in MAP bags were between 0.44 and 0.75 . The results indicate that SL increases weight loss and 


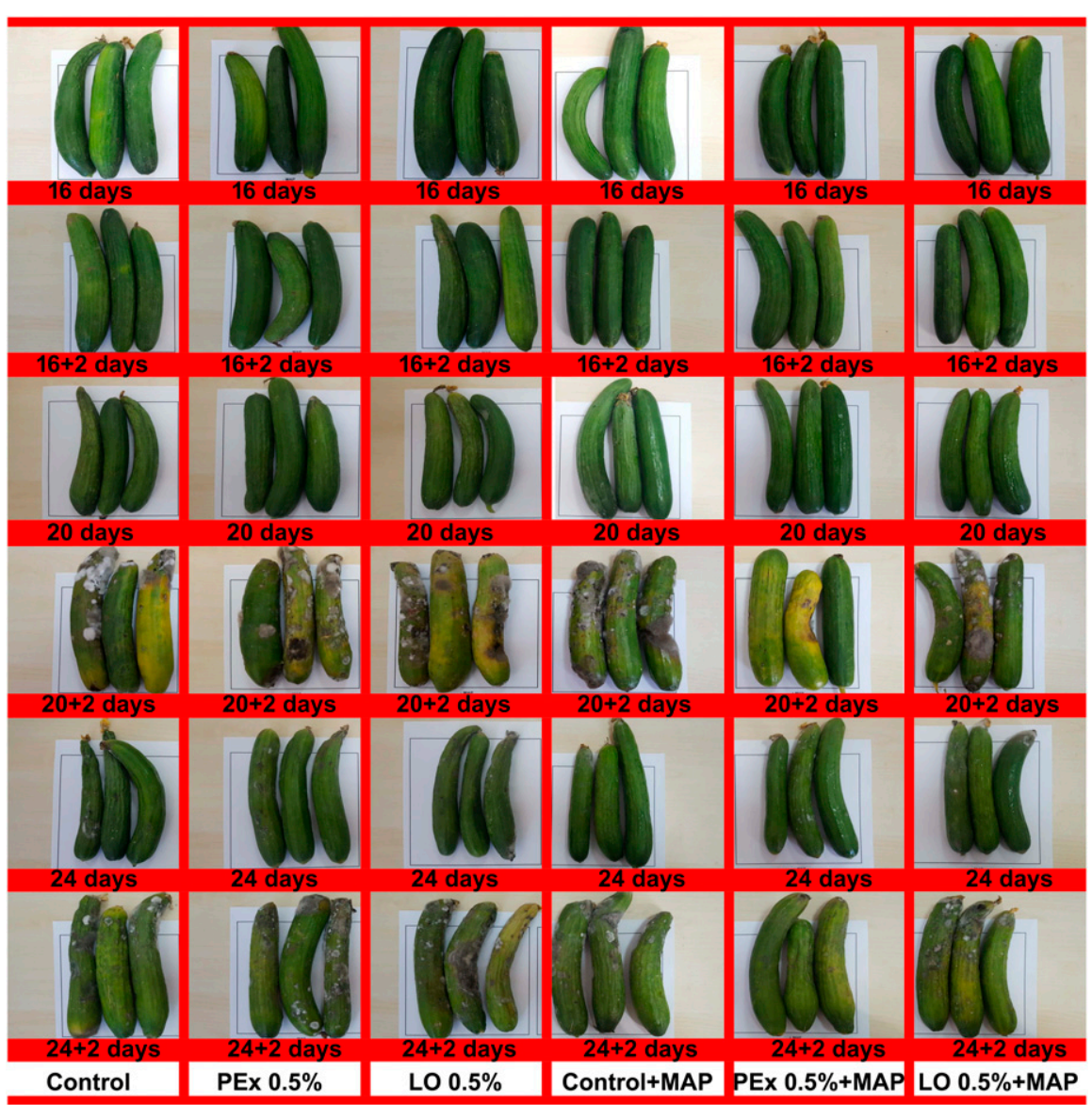

Fig. 7. Appearance of control and treated cucumbers during storage. $\mathrm{LO}=$ lemongrass oil; $\mathrm{MAP}=$ modified atmosphere packaging; PEx = propolis extract.

CI and also reduces sensory quality. The appearance of the fruits after $16 \mathrm{~d}$ of storage is shown in Fig. 7. Storing fruits in MAP bags was found to protect sensory quality for $20 \mathrm{~d}$ of storage (score of 1.00 to 1.50). Fruits stored without MAP had moderate sensory quality scores $(\approx 3.00)$, which limits marketability. Two days SL after $20 \mathrm{~d}$ of storage caused a significant loss in the sensory quality, with scores indicating heavy damage (of limited edible quality) for all fruits except those treated with MAP $+0.5 \%$ PEx. Thereafter, all fruits had a score of $>3.00$ (moderate) and were considered unsuitable for sale. Shelf life after $24 \mathrm{~d}$ of storage caused loss in quality for all fruits, with sensory scores measured as 5.00 for all treatments.

\section{Discussion}

Weight loss is an important indicator of the postharvest quality of fresh produce. It is mainly a result of two biological processes respiration and transpiration-and is highly affected by environmental conditions. It is also associated with loss of vitamins, browning, texture loss, and susceptibility to decay (Kader, 1991; Valverde et al., 2005). Therefore, prevention of the weight loss is a crucial step for maintaining the postharvest quality of fresh produce. In the present study, fruits in all treatments showed an increasing trend for weight loss during storage, but MAP was found to be effective in the prevention of weight loss. The ability of MAP to prevent weight loss was previously reported by several researchers for various fruits (Caleb et al., 2013; Dhall et al., 2012; Kahramanoğlu et al., 2018) and for cucumber fruits (Manjunatha and Anurag, 2014; Wang and Qi, 1997). In addition, application of PEx and LO was found to reduce weight loss of cucumber fruit, in agreement with previous studies carried out on different fruits (Kahramanoğlu 2019; Kahramanoğlu et al., 2018; Özdemir et al., 2010; Prakash et al., 2015; Zahid et al., 2013). Results also suggest that the combination of MAP with LO or PEx better prevents weight loss. Kahramanoğlu et al. (2018) and Kahramanoğlu (2019) presented similar results for different crops with PEx, LO, and black seed oil treatments.

Fruit firmness was maintained when stored in flexible MAP bags with or without LO and PEx. Jia et al. (2018) previously noted that the fruit firmness of cucumbers might be protected with application of putrescine. This was also found to be effective in preventing loss of SSC. MAP, LO, and PEx have been previously noted to prevent loss of fruit firmness and SSC in various fruits (Kahramanoğlu 2019; Kahramanoğlu et al., 2018; Özdemir et al., 2010; Zahid et al., 2013). Fruit firmness, including crispness and juiciness, is an important component of fruit texture (Konopacka and Plocharski, 2004). The main cause of firmness loss in fruits and vegetables is pectin depolymerization. MAP change the surrounding atmosphere of fruits by reducing $\mathrm{O}_{2}$ levels and increasing $\mathrm{CO}_{2}$ levels; according to Maftoonazad and Ramaswamy (2005), this reduces the activities of pestinesterase, which in turn allows the retention of fruit firmness. A similar mechanism was reported for edible coatings and essential oils by Zhang et al. (2014) and Mohammadi et al. (2016) for gum Arabic coating and Zataria multiflora EOs. Researchers have noted that coated cucumbers have reduced respiration, and this might be responsible for the retention of fruit firmness during storage. Similar successful results for edible coatings and EOs have been noted for various fruits and vegetables (Abdolahi et al., 2010; Eshghi et al., 2014).

$\mathrm{CI}$ is a serious problem, affecting many fruits and vegetables. Storing fruits at low but not freezing temperatures leads to the development of CI. It is a well-known phenomenon that CI symptoms mainly appear some days after storing at low temperatures. This was observed in the present study, where SL conditions were found to increase CI symptoms in fruits. The results suggest that MAP is effective in maintaining fruit resistance to $\mathrm{CI}$ and that application of PEx and LO further increases this efficacy. Wang (1989) reported that diverse physiological and biochemical alterations are seen in sensitive species when they are kept at low temperatures and fruits develop diverse CI symptoms, including surface pitting, discoloration, internal breakdown, loss of flavor, and decay. Intermittent warming, MAP, and application of synthetic and/or biochemicals were previously noted to be effective in alleviating the CI. In agreement with this, our results show that MAP is effective in preventing $\mathrm{CI}$ in cucumber fruits. Liu et al. (2016) previously noted that the postharvest application of methyl jasmonate and nitric oxide inhibits $\mathrm{H}_{2} \mathrm{O}_{2}$ accumulation in cucumber fruits and reduces CI. No similar studies were found for LO, but PEx was previously reported by Kahramanoğlu et al. (2018) to reduce CI on pomegranate fruits during storage.

CI generally increases fruits' susceptibility to decay (DeEll et al., 2000). The DI of cucumber fruits in the present study was similar to the CI results in that MAP was found to protect fruit from decay. The positive effects of MAP were further increased with the application of LO or PEx. Several researchers have reported similar positive effects for the three treatments in controlling fruit decay (Kahramanoğlu, 2019; Kahramanoğlu et al., 2018; Özdemir et al., 2010; Prakash et al., 2015; Zahid et al., 2013). However, most of these studies considered only a single treatment in isolation; few considered their combined effects, and no studies were on cucumber fruits. The success of propolis in controlling fruit decay in cucumbers is in agreement with the reports of Brasil et al. (2012), who noted that polysaccharide-based edible coatings are effective in protecting the microbiological 
quality of fresh-cut papaya. EOs of other plants were previously noted to be effective in controlling fruit decay in cucumber. For example, Mohammadi et al. (2016) noted that EO of Zataria multiflora controls microbial growth and improves the SL of cucumbers.

\section{Conclusions}

On the basis of our results, MA packaging was found to have important effects for preserving the quality parameters of cucumber fruits. Moreover, it was also concluded that the application of PEx and LO provides favorable conditions for cucumber fruits and improves postharvest storage quality. The combination of MAP with PEx or LO was found to have the highest impact on the quality parameters, and results suggested that the storage of cucumber fruits (under $4.5 \pm$ $0.5^{\circ} \mathrm{C}$ and $95 \% \mathrm{RH}$ ) might be extended to 20 d. Cucumber fruits are known to be sensitive to storage conditions and storage duration was limited to less than $14 \mathrm{~d}$. Reaching $20 \mathrm{~d}$ of storage with acceptable quality for edibility is an important result for the science and future of postharvest technology. These results reveal that combining MAP with EOs or other edible biomaterials improves its efficacy and provides higher quality fresh produce. Finally, because SL significantly reduces the quality of cucumber fruits and fruits stored on the shelf in MAP bags show higher quality than fruits stored without MAP bags, it is suggested that the fruits be transferred to consumers in MAP bags to preserve fruit quality.

\section{Literature Cited}

Abdolahi, A., A. Hassani, Y. Ghosta, I. Bernousi, and M. Meshkatalsadat. 2010. Study on the potential use of essential oils for decay control and quality preservation of Tabarzeh table grape. J. Plant Prot. Res. 50(1):45-52.

Adiletta, G., M.S. Pasquariello, L. Zampella, F. Mastrobuoni, M. Scortichini, and M. Petriccione. 2018. Chitosan coating: A postharvest treatment to delayoxidative stress in loquat fruits during cold storage. Agron. 8(4):54.

Bahnasawy, A.H. and E. Khater. 2014. Effect of wax coating on the quality of cucumber fruits during storage. J. Food Process. Technol. 5(339):2.

Brasil, I., C. Gomes, A. Puerta-Gomez, M. Castell-Perez, and R. Moreira. 2012. Polysaccharide-based multilayered antimicrobial edible coating enhances quality of fresh-cut papaya. Lebensm. Wiss. Technol. 47:39-45

Caleb, O., P. Mahajan, and U. Opara. 2013. Modified atmosphere packaging technology of fresh and fresh-cut produce and the microbial consequences - a review. Food Bioprocess Technol. 6:303-329.

Cao, S., Y. Zheng, and Z. Yang. 2011. Effect of $1-\mathrm{MCP}$ treatment on nutritive and functional properties of loquat fruit during cold storage. New Zeal. J. Crop Hort. 39(1):61-70.

Carmo, E.S., E. Lima, O.E.L. Souza, and F.B. Sousa. 2008. Effect of Cinnamomum zeylanicum Blume essential oil on the growth and morphogenesis of some potentially pathogenic Aspergillus species. Braz. J. Microbiol. 39:9197.
Coulibaly, O., T. Nouhoheiflin, C.C. Aitchedji, A.J. Cherry, and P. Adegbola. 2011. Consumers' perceptions and willingness to pay for organically grown vegetables. Int. J. Veg. Sci. 17(4):349-362.

Dang, K.T.H., Z. Singh, and E.E. Swinny. 2008. Edible coatings influence fruit ripening, quality, and aroma biosynthesis in mango fruit. J. Agr. Food Chem. 56(4):1361-1370.

Day, B.P.F. 2001. Modified atmosphere packaging of fresh fruit and vegetables - an overview. Acta Hort. 553(2):585-590.

de Sousa, J.P., G.A. de Azerêdo, R. de Araújo Torres, M.A. da Silva Vasconcelos, M.L. da Conceição, and E.L. de Souza. 2012. Synergies of carvacrol and 1,8-cineole to inhibit bacteria associated with minimally processed vegetables. Int. J. Food Microbiol. 154:145-151.

DeEll, J.R., C. Vigneault, and S. Lemerre. 2000. Water temperature for hydrocooling field cucumbers in relation to chilling injury during storage. Postharvest Biol. Technol. 18:27-32.

Dhall, R.K., S.R. Sharma, and B.V.C. Mahajan. 2012. Effect of shrink wrap packaging for maintaining quality of cucumber during storage. J. Food Sci. Technol. 49(4):495-499.

Dong, J., Q. Yu, L. Lu, and M. Xu. 2012. Effect of yeast saccharide treatment on nitricoxide accumulation and chilling injury in cucumber fruit during cold storage. Postharvest Biol. Technol. $68: 1-7$.

Eshghi, S., M. Hashemi, A. Mohammadi, F. Badii, Z. Mohammadhoseini, and K. Ahmadi. 2014 Effect of nanochitosan-based coating with and without copper loaded on physicochemical and bioactive components of fresh strawberry frui (Fragaria $\times$ ananassa Duchesne) during storage. Food Bioprocess Technol. 7(8):2397-2409.

Gatto, M.A., L. Sergio, A. Ippolito, and D. Di Venere. 2016. Phenolic extracts from wild edible plants to control postharvest diseases of sweet cherry fruit. Postharvest Biol. Technol. 120:180-187.

Gil, M.I., D.M. Holcroft, and A.A. Kader. 1997. Changes in anthocyanins and other polyphenols in response to carbon dioxide treatments. J. Agr. Food Chem. 45(5):1662-1667.

Glowacz, M., R. Colgan, and D. Rees. 2015. Influence of continuous exposure to gaseous ozone on the quality of red bell peppers, cucumbers and zucchini. Postharvest Biol. Technol. 99:1-8.

Gutiérrez-Martínez, P., A. Ramos-Guerrero, C. Rodríguez-Pereida, L. Coronado-Partida, J. Angulo-Parra, and R. González-Estrada. 2018 Chitosan for postharvest disinfection of fruits and vegetables, p. 231-241. In: M.W. Siddiqui (ed.). Postharvest disinfection of fruits and vegetables. Elsevier Academic Press, London, UK

Han, C., J. Zuo, Q. Wang, L. Xu, Z. Wang, H. Dong, and L. Gao. 2015. Effects of 1-MCP on postharvest physiology and quality of bitter melon (Momordica charantia L.). Scientia Hort. 182:86-91.

Jia, B., Q. Zheng, J. Zuo, L. Fao, Q. Wang, W. Guanf, and J. Shi. 2018. Application of postharvest putrescine treatment to maintain the quality and increase the activity of antioxidative enzyme of cucumber. Scientia Hort. 239:210-215.

Kader, A.A. 1991. Quality and its maintenance in relation to the postharvest physiology of strawberry, p. 145-152. In: A. Dale and J.J. Luby (eds.). The strawberry into the 21 st century. Timber Press, Portland, OR.

Kahramanoğlu, İ. 2019. Effects of lemongrass oil application and modified atmosphere packag- ing on the postharvest life and quality of strawberry fruits. Scientia Hort. 256 (in press)

Kahramanoğlu, İ., M. Aktaş, and Ş. Gündüz. 2018. Effects of fludioxonil, propolis and black seed oil application on the postharvest quality of "Wonderful" pomegranate. PLoS One 13(5):e0198411.

Koch, S., A. Epp, M. Lohmann, and G.F. Böl. 2017. Pesticide residues in food: attitudes, beliefs, and misconceptions among conventional and organic consumers. J. Food Prot. 80(12):2083-2089.

Konopacka, D. and W. Plocharski. 2004. Effect of storage conditions on the relationship between apple firmness and texture acceptability. Postharvest Biol. Technol. 32:205-211.

Liu, Y., X. Yang, S. Zhu, and Y. Wang. 2016. Postharvest application of MeJA and NO reduced chilling injury in cucumber (Cucumis sativus) through inhibition of $\mathrm{H} 2 \mathrm{O} 2$ accumulation. Postharvest Biol. Technol. 119:77-83.

Maftoonazad, N. and H. Ramaswamy. 2005. Postharvest shelf-life extension of avocados using methyl cellulose-based coating. Lebensm. Wiss. Technol. 38(6):617-624.

Manjunatha, M. and R.K. Anurag. 2014. Effect of modified atmosphere packaging and storage conditions on quality characteristics of cucumber. J. Food Sci. Technol. 51(11):3470-3475.

Martin-Belloso, O. and R.S. Fortuny. 2011. Advances in fresh-cut fruits and vegetables processing. CRC Press, Boca Raton, FL.

Mohammadi, A., M. Hashemi, and S.M. Hosseini. 2016. Postharvest treatment of nanochitosanbased coating loaded with Zataria multiflora essential oil improves antioxidant activity and extends shelf-life of cucumber. Innov. Food Sci. Emerg. 33:580-588

Nasef, I.N. 2018. Short hot water as safe treatment induces chilling tolerance and antioxidant enzymes, prevents decay and maintains quality of cold-stored cucumbers. Postharvest Biol. Technol. 138:1-10.

Obagwu, J. and L. Korsten. 2003. Control of citrus green and blue molds with garlic extracts. Eur. J. Plant Pathol. 109(3):221-225.

Özdemir, A.E., E.E. Çandır, M. Kaplankıran, E.M. Soylu, N. Şahinler, and A. Gül. 2010. The effects of ethanol-dissolved propolis on the storage of grapefruit cv. Star Ruby. Turk. J. Agric. For. 34:155-162.

Panahirad, S., R. Naghshiband-Hassani, B. Ghanbarzadeh, F. Zaare-Nahandi, and N. Mahna. 2019. Shelf life quality of plum fruits (Prunus domestica L.) improves with carboxymethylcellulose-based edible coating. HortScience 54:505-510.

Pavela, R. and G. Benelli. 2016. Essential oils as eco friendly biopesticides? Challenges and constraints. Trends Plant Sci. 21(12):10001007.

Prakash, B., A. Kedia, P.K. Mishra, and N.K. Dubey. 2015. Plant essential oils as food preservatives to control moulds, mycotoxin contamination and oxidative deterioration of agri-food commodities-Potentials and challenges. Food Control 47:381-391.

Saucedo-Pompa, S., R. Rojas-Molina, A.F. AguileraCarbó, A. Saenz-Galindo, G.H. de La, D. JassoCantú, and C.N. Aguilar. 2009. Edible film based on candelilla wax to improve the shelf life and quality of avocado. Food Res. Int. 42(4):511-515.

Sharif, R., M. Mujtaba, M. Ur Rahman, A. Shalmani, H. Ahmad, T. Anwar, D. Tianchan, and W. Wang. 2015. The multifunctional role of chitosan in horticultural crops; A review. Molecules 23(4): 8872.

Sharma, R.R., D. Singh, and R. Singh. 2009. Biological control of postharvest diseases of 
fruits and vegetables by microbial antagonists: A review. Biol. Control 50(3):205-221

Shi, J., J. Wang, R. Li, D. Li, F. Xu, Q. Sun, B. Zhao, A. Mao, and Y. Guo. 2015. Expression patterns of genes encoding plasma membrane aquaporins during fruit development in cucumber (Cucumis sativus L.). Plant Physiol. Biochem. 96:329-336.

Silvestre, C., D. Duraccio, and S. Cimmino. 2011. Food packaging based on polymer nanomaterials. Prog. Polym. Sci. 36(12):1766-1782.

Troyo, R.D. and A.L. Acedo. 2019. Effects of calcium ascorbate and calcium lactate on quality of fresh-cut pineapple (Ananas comosus). Int. J. Agr. For. Life Sci. 3(1):143-150.
Valverde, J.M., F. Guillén, D. Martínez-Romero, S. Castillo, M. Serrano, and D. Valero. 2005. Improvement of table grapes quality and safety by the combination of modified atmosphere packaging (MAP) and eugenol, menthol, or thymol. J. Agr. Food Chem. 53(19):7458 7464.

Wang, B. and S. Zhu. 2017. Pre-storage cold acclimation maintained quality of cold-stored cucumber through differentially and orderly activating ROS scavengers. Postharvest Biol. Technol. 129:1-8.

Wang, C.Y. 1989. Chilling injury of fruits and vegetables. Food Rev. Int. 5(2):209-236.
Wang, C.Y. and L. Qi. 1997. Modified atmosphere packaging alleviates chilling injury in cucumbers. Postharvest Biol. Technol. 10:195-200.

Zahid, N., A. Ali, Y. Siddiqui, and M. Maqbool 2013. Efficacy of ethanolic extract of propolis in maintaining postharvest quality of dragon fruit during storage. Postharvest Biol. Technol. 79:69-72.

Zhang, Y., Y. Niu, Y. Luo, M. Ge, T. Yang, L.L. $\mathrm{Yu}$, and Q. Wang. 2014. Fabrication, characterization and antimicrobial activities of thymol-loaded zein nanoparticles stabilized by sodium caseinate-chitosan hydrochloride double layers. Food Chem. 142:269275. 